\title{
Growth Promotion of Giant Duckweed Spirodela polyrhiza (Lemnaceae) by Ensifer sp. SP4 Through Enhancement of Nitrogen Metabolism and Photosynthesis
}

\author{
Tadashi Toyama, ${ }^{1,}$ Kazuhiro Mori, ${ }^{1}$ Yasuhiro Tanaka, ${ }^{1}$ Michihiko Ike, ${ }^{2}$ and Masaaki Morikawa ${ }^{3}$ \\ ${ }^{1}$ Graduate Faculty of Interdisciplinary Research, University of Yamanashi, 4-3-11 Takeda, Kofu, Yamanashi 400-8511, Japan \\ ${ }^{2}$ Division of Sustainable Energy and Environmental Engineering, Osaka University, 2-1 Yamadaoka, Suita, Osaka 565-0871, \\ Japan \\ ${ }^{3}$ Division of Biosphere Science, Graduate School of Environmental Science, Hokkaido University, Kita-10 Nishi-5, Kita-ku, \\ Sapporo 060-0810, Japan
}

Accepted 20 September 2021.

Duckweeds (Lemnaceae) are representative producers in fresh aquatic ecosystems and also yield sustainable biomass for animal feeds, human foods, and biofuels, and contribute toward effective wastewater treatment; thus, enhancing duckweed productivity is a critical challenge. Plant-growth-promoting bacteria (PGPB) can improve the productivity of terrestrial plants; however, duckweed-PGPB interactions remain unclear and no previous study has investigated the molecular mechanisms underlying duckweed-PGPB interaction. Herein, a PGPB, Ensifer sp. strain SP4, was newly isolated from giant duckweed (Spirodela polyrhiza), and the interactions between $S$. polyrhiza and SP4 were investigated through physiological, biochemical, and metabolomic analyses. In S. polyrhiza and SP4 coculture, SP4 increased the nitrogen $(\mathrm{N})$, chlorophyll, and ribulose-1,5-bisphosphate carboxylase/oxygenase (RuBisCO) contents and the photosynthesis rate of $S$. polyrhiza by 2.5-, 2.5-, 2.7-, and 2.4-fold, respectively. Elevated photosynthesis increased the relative growth rate and biomass productivity of $S$. polyrhiza by 1.5 and 2.7-fold, respectively. Strain SP4 significantly altered the metabolomic profile of $S$. polyrhiza, especially its amino acid profile. $\mathrm{N}$ stable isotope analysis revealed that organic $\mathbf{N}$ compounds were transferred from SP4 to S. polyrhiza. These N compounds, particularly glutamic acid, possibly triggered the increase in photosynthetic and growth activities. Accordingly, we propose a new model for the molecular mechanism underlying $S$. polyrhiza growth promotion by its associated bacteria Ensifer sp. SP4, which occurs through enhanced N compound metabolism and photosynthesis. Our findings show that Ensifer sp. SP4 is a promising PGPB for increasing

${ }^{\dagger}$ Corresponding author: T. Toyama; ttohyama@yamanashi.ac.jp

Funding: Japan Science and Technology Agency, Advanced Low-Carbon Technology Research and Development Program, grant number JPMJAL1108; and Ministry of Education, Culture, Sports, Science and Technology of Japan, grant numbers 60431392 and 19K04663.

*The $\boldsymbol{e}$-Xtra logo stands for "electronic extra" and indicates that supplementary materials are published online.

The author(s) declare no conflict of interest.

(c) (1) () $\odot$ Copyright $(02021$ The Author(s). This is an open access article cc) biomass yield, wastewater purification activity, and $\mathrm{CO}_{2}$ capture of S. polyrhiza.

Keywords: duckweed, Ensifer sp., nitrogen metabolism, photosynthesis, plant-bacteria interaction, plant-growth-promoting bacteria, Spirodela polyrhiza

Duckweeds (Lemnaceae) are the smallest free-flowing aquatic plants having a global distribution in freshwater environments (Landolt and Kandeler 1987); they are morphologically simple, with zero or few roots and rudimentary leaf structure, designated fronds (Appenroth et al. 2013; Landolt and Kandeler 1987). They primarily propagate via asexual reproduction (i.e., new daughter fronds originate from a mother frond) (Appenroth et al. 2013; Landolt and Kandeler 1987), and they exhibit higher growth rates than those of other higher plants (Ziegler et al. 2015). Duckweeds are important and representative primary producers in fresh aquatic ecosystems and have applications in wastewater treatment and environmental water purification due to their rapid growth and high nutrient removal properties (Cheng and Stomp 2009; Mohedano et al. 2012; Toyama et al. 2018). Furthermore, their high protein and starch content makes them a promising feedstock for industrial protein (Xu et al. 2012a), animal feed (Cheng and Stomp 2009; van der Spiegel et al. 2013), human food (Appenroth et al. 2017; van der Spiegel et al. 2013), and biofuels (Cui and Cheng, 2015; Xu et al. 2012b). Enhancing duckweed growth is a critical challenge for duckweed-based applications; hence, it is important to understand the mechanisms underlying duckweed growth to develop appropriate strategies to promote duckweed growth.

Similar to terrestrial plants, duckweeds also coexist with bacterial communities in aquatic ecosystems (Acosta et al. 2020; Iwashita et al. 2020), which affect the growth and health of the host duckweed (Ishizawa et al. 2017a). Certain bacteria, called plant-growth-promoting bacteria (PGPB) (Bashan and Holguin 1998), provide benefits to their host plants via various ways such as nitrogen $(\mathrm{N})$ fixation, phosphorus $(\mathrm{P})$ solubilization, and siderophore and phytohormone production (Bulgarelli et al. 2013). Several PGPB have been isolated from duckweeds, including Acinetobacter calcoaceticus P23 from the duckweed species Lemna aequinoctialis (Yamaga et al. 2010), Aquitalea magnusonii $\mathrm{H} 3$ from L. minor (Ishizawa et al. 2017a), and Chryseobacterium sp. 27AL from L. gibba (Khairina et al. 2021). Moreover, phytohormone indole-3-acetic acid (IAA)-producing endophytic 
bacteria have been isolated from duckweeds (Gilbert et al. 2018). Interactions between duckweeds and PGPB is an interesting topic in the field of aquatic plant physiology and microbiology, and are important for the primary productivity of fresh aquatic ecosystems. Moreover, exploitation of PGPB can increase biomass yields (Ishizawa et al. 2020), enable sustainable biomass production under stress conditions (Ishizawa et al. 2017b), and enhance water purification performance (Ishizawa et al. 2020) of duckweeds.

However, compared with studies on terrestrial plants, few studies have been conducted on PGPB for duckweeds. To the best our knowledge, no previous study has investigated the molecular mechanisms underlying the promotion of duckweed growth by PGPB (i.e., duckweed-PGPB interactions). Elucidating this will improve our understanding of duckweed growth in aquatic ecosystems and contribute to the development of practical PGPB applications that increase the performance of duckweed-based wastewater treatment systems, as well as the starch- and proteinbiomass production yield of duckweed culture.

Therefore, we sought to elucidate the molecular mechanisms of interactions between duckweed and PGPB involved in enhancing duckweed biomass production. We newly isolated the PGPB Ensifer sp. strain SP4 from Spirodela polyrhiza (L.) Schleid. (giant duckweed) and conducted phylogenetic and physiological analyses. Next, we examined the growth, physiological (photosynthesis), and biochemical (carbon [C], N, chlorophyll, starch, and protein content; $\mathrm{C}$ and $\mathrm{N}$ stable isotope ratios $\left[\delta^{13} \mathrm{C}={ }^{13} \mathrm{C} /{ }^{12} \mathrm{C}\right.$ and $\left.\delta^{15} \mathrm{~N}={ }^{15} \mathrm{~N} /{ }^{14} \mathrm{~N}\right]$ ) responses of $S$. polyrhiza to SP4 in coculture. We also characterized changes in the metabolomic profile of $S$. polyrhiza in response to SP4. Finally, we discussed the molecular mechanisms underlying plant-bacteria interaction contributing to enhanced $S$. polyrhiza growth by integrating physiological, biochemical, stable isotope, and metabolomic data.

\section{RESULTS}

Isolation and characterization of Ensifer sp. SP4.

In total, 11 bacterial strains were isolated from the surfaces of S. polyrhiza grown in municipal wastewater effluent. Strain SP4 was selected for further study because it exhibited the highest S. polyrhiza growth-promoting activity among all tested strains under the same inoculation cell density conditions (Supplementary Table S1). SP4 formed white slimy colonies on 1:10 diluted tryptic soy agar. SP4 was positive for oxidase, urease, esculin hydrolysis, $\beta$-galactosidase, and nitrate reduction activities, whereas it was negative for glucose fermentation, indole production, arginine dihydrolase, and gelatinase activities. SP4 utilized glucose, L-arabinose, D-mannose, D-mannitol, N-acetyl-D-glucosamine, maltose, or D,L-malate as sole $\mathrm{C}$ sources but did not utilize gluconate, $n$-caprate, adipate, citrate, or phenylacetate. The $16 \mathrm{~S}$ ribosomal RNA (rRNA) gene sequences $(1,405 \mathrm{bp}$ ) of SP4 exhibited $100 \%$ similarity $(1,405$ of 1,405$)$ with that of Ensifer adhaerens strain NBRC $100388^{\mathrm{T}} / \mathrm{LMG} 20216^{\mathrm{T}}$ (previously reported as Sinorhizobium adhaerens) (Willems et al. 2003) 99.7\% similarity $(1,381$ of 1,385$)$ with that of E. sesbaniae strain CCBAU $65729^{\mathrm{T}}$, $99.2 \%$ similarity $(1,396$ of 1,407$)$ with that of $S$. fredii strain NBRC $14780^{\mathrm{T}}$, and $99.2 \%$ similarity $(1,396$ of 1,407$)$ with that of S. americanum strain CFNEI $156^{\mathrm{T}}$. Based on the phylogenetic analysis, SP4 was identified as an Ensifer sp. In terms of the typical plant-growth-promoting factors (IAA-producing, siderophoreproducing, P-solubilizing, and N-fixing activities) of PGPB, SP4 was positive for only siderophore-producing activity and negative for IAA-producing, P-solubilizing, and $\mathrm{N}$-fixing activities.

\section{Changes in growth and physiological and biochemical} characteristics of Spirodela polyrhiza after coculture with SP4.

To examine the growth-promoting effects of SP4 on Spirodela polyrhiza, S. polyrhiza was cocultured with or without SP4 (sterile control) in Hoagland medium for 5 days. The frond number and dry weight of S. polyrhiza in coculture with SP4 were significantly higher $(P<0.05)$ than those in sterile control culture as early as after 3 days (Fig. $1 \mathrm{~A}$ and B). The relative growth rate $\left(0.548 \pm 0.009 \mathrm{day}^{-1}\right)$ of $S$. polyrhiza in a 5-day coculture with SP4 was 1.5 times higher than that of the sterile $S$. polyrhiza control culture $\left(0.361 \pm 0.012\right.$ day $\left.^{-1}\right)$ (Fig. 1C). The $S$. polyrhiza biomass production rate $\left(27.4 \mathrm{mg}\right.$ dry weight day $\left.{ }^{-1}\right)$ in a 5-day coculture with SP4 was also 2.7 times higher than that in $S$. polyrhiza sterile culture $\left(10.1 \mathrm{mg}\right.$ dry weight day $\left.{ }^{-1}\right)$ (Fig. 1D). The mature frond size ( 8 by $8 \mathrm{~mm}$ ) and dry weight of a single $S$. polyrhiza plant that includes some fronds and roots $(0.54 \mathrm{mg})$ in coculture with SP4 were slightly larger than those ( 7 by $7 \mathrm{~mm}$ and $0.46 \mathrm{mg}$ ) of $S$. polyrhiza in the sterile control (Supplementary Fig. S1). Moreover, root length $(18 \mathrm{~mm})$ of $S$. polyrhiza in coculture with SP4 was shorter than that $(27 \mathrm{~mm})$ of $S$. polyrhiza in the sterile control (Supplementary Fig. S1), suggesting a superior nutrient condition for $S$. polyrhiza in coculture with SP4 (Giehl and von Wirén 2014; Hodge 2004).

The chlorophyll $a+b$ content, ribulose-1,5-bisphosphate carboxylase/oxygenase (RuBisCO) content, and photosynthetic rate of $S$. polyrhiza increased after coculture with SP4 and became significantly higher $\left(P<0.05 ; 34.6 \mu \mathrm{g} \mathrm{g}^{-1}, 0.162 \mathrm{~g} \mathrm{~g}^{-1}\right.$, and $1.05 \mu \mathrm{mol} \mathrm{CO}_{2} \mathrm{~s}^{-1} \mathrm{~g}^{-1}$, respectively) than those in sterile control culture $\left(14.1 \mu \mathrm{g} \mathrm{g}^{-1}, 0.0595 \mathrm{~g} \mathrm{~g}^{-1}\right.$, and $0.43 \mu \mathrm{mol} \mathrm{CO} \mathrm{CO}^{-1} \mathrm{~g}^{-1}$, respectively) after 5 days, representing an increase of $2.5,2.7$, and 2.4 times (Fig. 2A to C).

$\mathrm{C}$ and $\mathrm{N}$ content $(\%)$ in $S$. polyrhiza biomass increased after coculture with SP4, whereas the content of $\mathrm{C}$ and $\mathrm{N}$ remained unchanged in the sterile control (Fig. 2D and F). After 5 days, the C $(48.1 \%)$ and $\mathrm{N}(6.3 \%)$ content in $S$. polyrhiza in coculture with SP4 were 1.3 and 2.5 times higher, respectively, than that
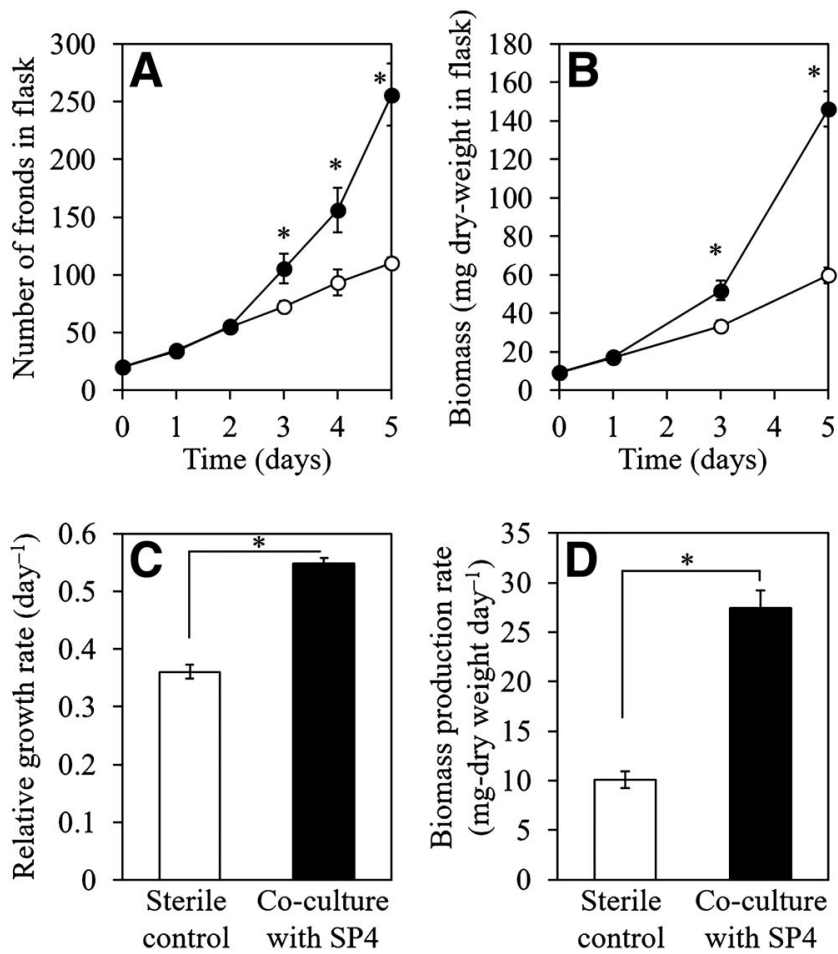

Fig. 1. Increase in $\mathbf{A}$, frond number and $\mathbf{B}$, dry weight biomass of Spirodela polyrhiza in coculture with SP4 (•) and in sterile control culture (०). C, Calculated relative growth rate and $\mathbf{D}$, biomass production rate of $S$. polyrhiza in coculture with SP4 and in sterile control culture based on the increase in dry weight biomass. Values are means \pm standard deviation. Asterisks indicate significant difference $(P<0.05)$ between the coculture with SP4 and the sterile control culture. 
in the sterile control. Values for $\delta^{13} \mathrm{C}$ and $\delta^{15} n(\%)$ in the $S$. polyrhiza biomass also increased after coculture with SP4 (Fig. 2E and $\mathrm{G}$ ); the $\delta^{13} \mathrm{C}$ value of SP4 was $-23.2 \%$. Specifically, after 5 days, the $\delta^{13} \mathrm{C}$ value $(-22.5 \%)$ of $S$. polyrhiza in coculture with SP4 was slightly but significantly higher $(P<$ $0.05)$ than that $(-23.9 \%)$ of $S$. polyrhiza in the sterile control.

SP4 cells alone cultured in 1:5 diluted tryptic soy medium until the late logarithmic growth phase showed $42.3 \% \mathrm{C}$ content, $11.6 \% \mathrm{~N}$ content, $-23.2 \% \delta^{13} \mathrm{C}$ value, and $5.5 \% \delta^{15} n$ value. The $\mathrm{N}$ content and $\delta^{15} n$ value of $\mathrm{KNO}_{3}$, which was used as the N source in S. polyrhiza culture Hoagland solution, was $13.7 \%$ and $-3.0 \%$, respectively. After 5 days, the $\delta^{15} n$ value $(3.5 \%$ of S. polyrhiza in coculture with SP4 was close to the value of SP4 cells; in contrast, the $\delta^{15} n$ value $(-0.9 \%$ of $S$. polyrhiza in the sterile control was closer to the value of $\mathrm{KNO}_{3}$. These results indicate that $S$. polyrhiza in coculture with SP4 absorbed the N compounds supplied from SP4.

The protein content of $S$. polyrhiza biomass in coculture with SP4 increased from 16.1 to $39.7 \%$ over the 5 days (Fig. $2 \mathrm{H}$ ). On day 5 , the protein content of $S$. polyrhiza in coculture with SP4 was 2.4 times higher than that in the sterile control $(16.3 \%)$, whereas the starch content of $S$. polyrhiza biomass in coculture with SP4 decreased from 19.0 to $14.7 \%$ over the 5 days (Fig. 2I). On day 5, the starch content of S. polyrhiza in coculture with SP4 was significantly lower than that in the sterile control (18.9\%), suggesting its healthy growth.

\section{Changes in the metabolomic profile of $S$. polyrhiza in coculture with SP4.}

In total, 58 metabolites, including 24 amino acids, 10 organic acids, 13 sugar phosphates, 5 nucleic acids, and 6 cofactors or coenzymes, were quantified by capillary electrophoresis time-offlight mass spectrometer (CE-TOFMS) analysis for both $S$. polyrhiza and SP4 extracted samples. The metabolites were classified by metabolic functions into group 1: Calvin cycle, glycolysis, and sugar metabolism; group 2: photorespiration; group 3: tricarboxylic acid (TCA) cycle; group 4: amino acid metabolism; group 5: nucleotides; and group 6: cofactors and coenzymes (Supplementary Table S2). The total metabolites in groups 1, 2, 3, 4, 5, and 6 in S. polyrhiza after coculture with SP4 were 1.2 to $1.4,2.0$ to 3.1, 0.4 to $0.6,3.2$ to $4.1,1.4$ to 2.1 , and 1.3 to 2.0 times higher, respectively, than those of $S$. polyrhiza in the sterile control (Supplementary Table S2). The amino acid concentrations in $S$. polyrhiza were particularly elevated after coculture with SP4. Hierarchical cluster analysis showed that the metabolomic profiles of SP4 cells, S. polyrhiza in the sterile control, and $S$. polyrhiza in coculture with SP4 were clearly different for each group (Supplementary Fig. S2). The wide difference in metabolic profiles between SP4 and S. polyrhiza cells should be due to a difference between bacteria (SP4) and plant (S. polyrhiza). Hierarchical cluster analysis also indicated that the levels of cofactors or coenzymes (glutathione [GSH], acetyl coenzyme A, nicotinamide adenine dinucleotide, coenzyme A, and S-adenosylmethionine) and nucleotides (AMP, adenosine, and adenine) were higher in SP4 cells. Specifically, levels of metabolites in photorespiration (Ser and Gly), TCA cycle (fumaric acid and Suc), amino acids (Orn, Arg, Ala, $\beta$-Ala, Pro, Val, Trp, His, Glu, $\gamma$-aminobutyric acid [GABA], Asp, Thr, Hse, Gln, citrulline, and Asn), nucleotides (ADP and ATP), and cofactor or coenzyme (NADP and glutathione disulfide [GSSG]) pathways were higher in S. polyrhiza coculture with SP4 from days 1 to 5; levels of metabolites in Calvin cycle, glycolysis, and sugar metabolism (dihydroxyacetone phosphate, glucose 1-phosphate, glucose 6-phosphate, fructose 6-phosphate, 6PGA, ribulose 5-phosphate, 3PGA, PEP, and 2PGA) and amino acid (Lys, Leu, Ile, Phe, and Tyr) pathways were higher in S. polyrhiza coculture with SP4 on days 3 and 5; and levels of metabolites in Calvin cycle, glycolysis, and sugar and starch syntheses (lactic acid, gluconic acid [GA], sedoheptulose 7-phosphate, ribose 5-phosphate, and Pyr) and TCA cycle (Mal, isocitric acid [Isocit], citric acid [Cit], cis-aconitic acid [cisAco], and 2-OG) pathways were higher in S. polyrhiza in the sterile control. More abbreviations of metabolite names are shown in Supplementary Table S2.

Changes in the metabolomic profile of $S$. polyrhiza in coculture with SP4 were summarized using metabolite fold-change (Fig. 3) and pathway maps (Fig. 4). The levels of metabolites involved in the Calvin cycle, glycolysis, sugar metabolism, photorespiration, and amino acid metabolic pathways typically increased in $S$. polyrhiza after coculturing with SP4. In contrast, the levels of metabolites of TCA, particularly Cit, cisAco, Isocit, and Mal, decreased in $S$. polyrhiza after coculture with SP4. These analyses revealed that the metabolomic profile of $S$. polyrhiza changed dramatically after coculture with SP4 and continued to change throughout the coculture.

\section{DISCUSSION}

In this study, Ensifer sp. SP4 - newly isolated from the surface of $S$. polyrhiza grown in municipal wastewater effluent-was capable of significantly promoting the growth of $S$. polyrhiza. Ensifer (Sinorhizobium) bacteria are members of the rhizobia group and are capable of establishing symbiosis with legumes and fixing atmospheric $\mathrm{N}$ into ammonia (Gopalakrishnan et al. 2015; Laranjo et al. 2014). Rhizobia can promote the growth of leguminous and nonleguminous plants accompanied by several beneficial effects such as $\mathrm{N}$ fixation, $\mathrm{P}$ solubilization, siderophore production, phytohormone (e.g., IAA) production, and increasing stress resistance (Gopalakrishnan et al. 2015; Laranjo et al. 2014). However, in the present study, SP4 did not exhibit N-fixation, P-solubilizing, or IAA-producing properties. Thus, the results suggest that growth promotion of the host $S$. polyrhiza by SP4 involves effects other than $\mathrm{N}$ fixation, $\mathrm{P}$ solubilization, and IAA production.

After 5 days of S. polyrhiza and SP4 coculture in Hoagland medium, the relative growth rate and biomass productivity of S. polyrhiza increased by 1.5 - and 2.7-fold, respectively, compared with $S$. polyrhiza in the sterile control. Indeed, enhanced biomass production of $S$. polyrhiza by SP4 was observed after as few as 3 days of coculture with SP4 (Fig. 1). Prior to this, $S$. polyrhiza showed several distinct physiological and biochemical responses to SP4. That is, the chlorophyll content, RuBisCO content, photosynthesis rate, and $\mathrm{N}$ content (Fig. 2), as well as the metabolomic characterization (Figs. 3 and 4; Supplementary Fig. S2) changed rapidly and significantly within 1 day of coculture with SP4. These responses should lead to enhanced biomass production of $S$. polyrhiza.

Biomass production of plants under photoautotrophic conditions depends on photosynthesis, which includes light-dependent reaction and Calvin cycle (Buchanan et al. 2015). Photosynthetic ability is highly correlated with the leaf $\mathrm{N}$ content of plants; $\mathrm{N}$ is allocated in chlorophylls, in the proteins of thylakoids, in proteins as part of the Calvin cycle, and in amino acids (Evans 1989; Perchlik and Tegeder 2018; Sudo et al. 2014). Chlorophylls represent a limiting factor of photosynthesis (Terry 1980) because they absorb light and function as the primary electron donor in the reaction center of photosystems I and II at thylakoids that produce nicotinamide adenine dinucleotide phosphate (NADPH) and ATP from light (Hipkins and Baker 1985). Photosynthesis, and related ATP production, depend on chlorophyll content and associated light capture. In the present study, the $\mathrm{N}$ and chlorophyll content of $S$. polyrhiza increased rapidly and significantly after 1 day of coculture with SP4 (Fig. 2); these values had highly positive correlations with each other (Supplementary Fig. S3). In fact, ATP and NADP, an oxidized form of NADPH, were significantly increased in S. polyrhiza after coculture with SP4 compared with 

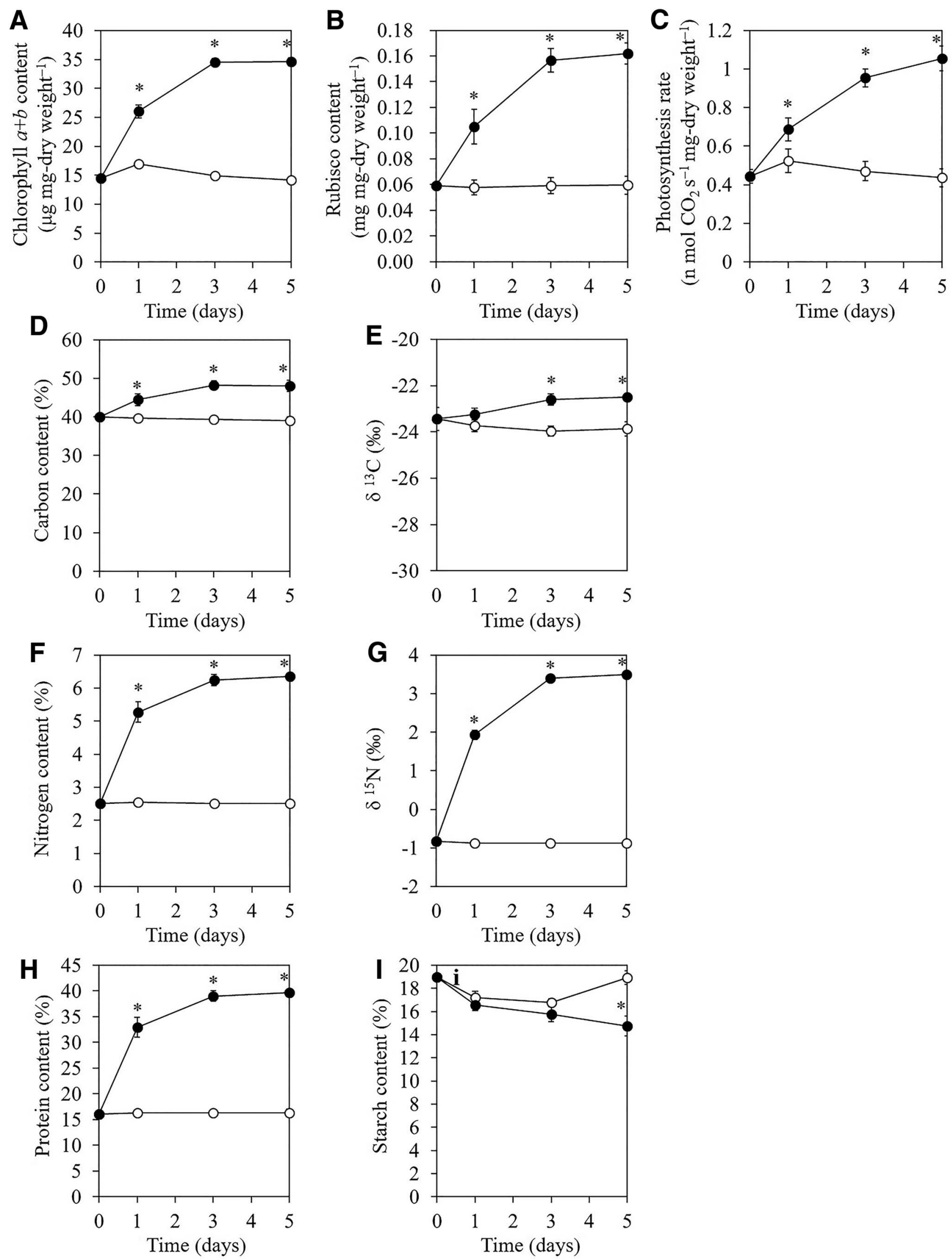

Fig. 2. Increase in $\mathbf{A}$, chlorophyll $a+b$ content; $\mathbf{B}$, ribulose-1,5-bisphosphate carboxylase/oxygenase (RuBisCO) content; $\mathbf{C}$, photosynthesis rate; $\mathbf{D}$, carbon (C) content; E, $\delta^{13} \mathrm{C}$ value; $\mathbf{F}$, Nitrogen $(\mathrm{N})$ content; $\mathbf{G}, \delta^{15} n$ value; $\mathbf{H}$, protein content; and $\mathbf{I}$, starch content in Spirodela polyrhiza in coculture with SP4 $(\bullet)$ and in sterile control culture $(\circ)$. Values are means \pm standard deviation. Asterisks indicate significant difference $(P<0.05)$ between the coculture with SP4 and the sterile control culture. 
those in sterile S. polyrhiza (Supplementary Table S2; Fig. 3). These results clearly indicate that the light-dependent reactions of S. polyrhiza were enhanced after coculture with SP4.

RuBisCO is a key enzyme in the Calvin cycle and a rate-limiting factor for photosynthesis (Makino 2003). In the Calvin cycle, a C from $\mathrm{CO}_{2}$ is fixed and bound to ribulose 1,5-bisphosphate (RuBP) to generate two 3PGA. RuBisCO then catalyzes the carboxylation process. Subsequently, 3PGA is reduced to glyceraldehyde 3-phosphate (GAP) using ATP and NADPH generated from the light-dependent reactions. Some GAP molecules are used for the synthesis of glucose molecules, whereas others are recycled to regenerate RuBP using ATP (Buchanan et al. 2015). In the present study, the RuBisCO content and photosynthesis rate $\left(\mathrm{CO}_{2}\right.$ absorption rate) of $S$. polyrhiza increased rapidly and significantly after 1 day of coculture with SP4 (Fig. 2). In fact, the concentrations of metabolites in the Calvin cycle in S. polyrhiza

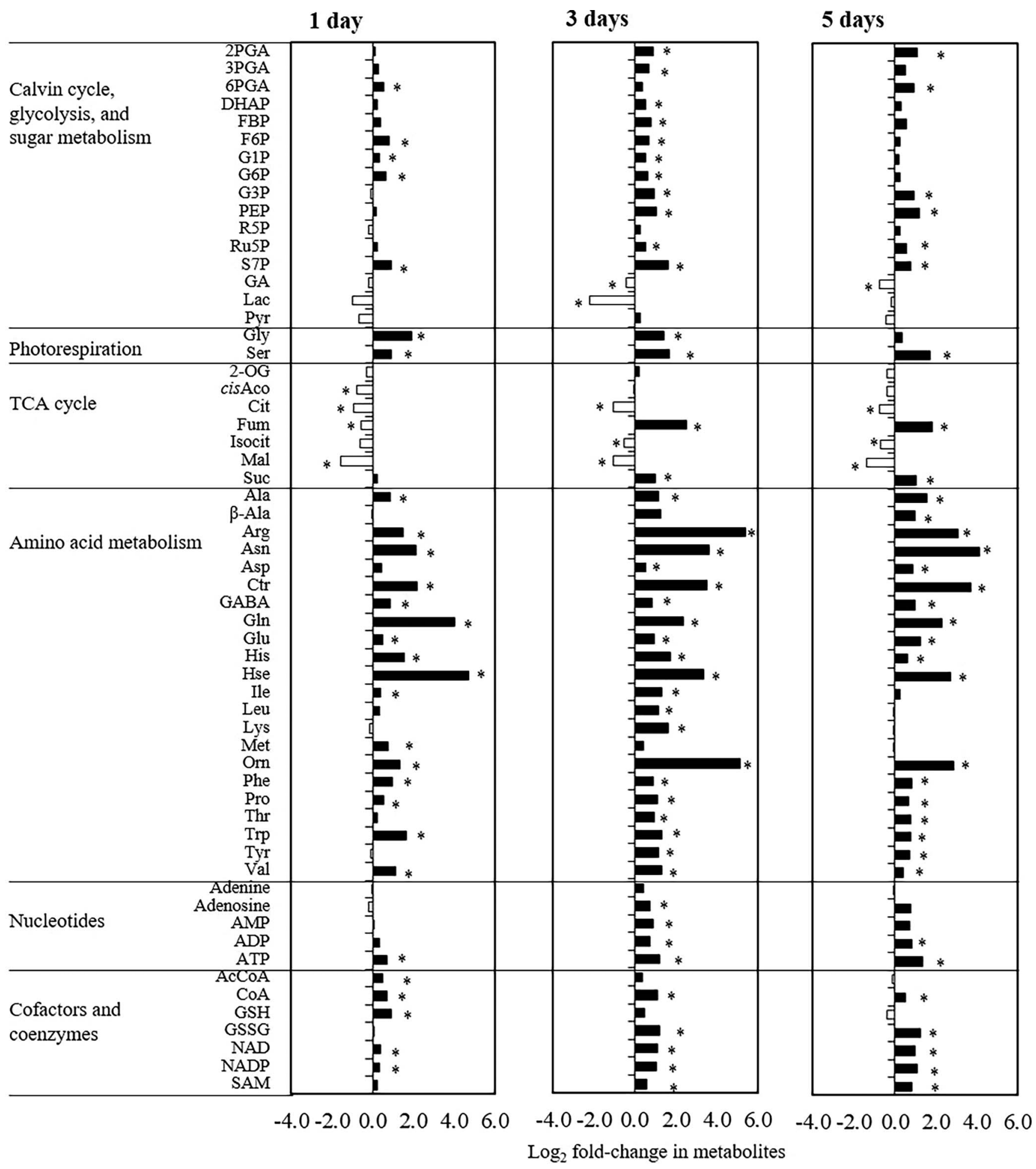

Fig. 3. Comparison of metabolite changes in Spirodela polyrhiza in coculture with SP4 and in sterile control culture on days 1,3 , and 5 . Log 2 foldchanges were determined as $\log _{2}$ (S. polyrhiza coculture with SP4 or sterile control). Black and white bars indicate positive and negative values of $\log _{2}$ fold-change, respectively. Asterisks indicate significant difference $(P<0.05)$. Abbreviations of metabolite names are defined in Supplementary Table S2. 
after coculture with SP4 were higher than those in sterile $S$. polyrhiza (Supplementary Table S2; Figs. 3 and 4). Hence, the Calvin cycle of $S$. polyrhiza was enhanced after coculture with SP4. RuBisCO content and photosynthesis rate also exhibited high positive correlations with $\mathrm{N}$ content in S. polyrhiza (Supplementary Fig. S3). Therefore, the enhanced photosynthesis was supported by the increased $\mathrm{N}$ content in $S$. polyrhiza after coculture with SP4.

In addition, the $\mathrm{C}$ isotope ratio $\left(\delta^{13} \mathrm{C}\right)$ in plants has a positive relationship with the degree of photosynthesis (Bevins et al. 1993; Hill et al. 1996). In the present study, the $\delta^{13} \mathrm{C}$ value in $S$. polyrhiza also increased after coculture with SP4 (Fig. 2), supporting the finding that the photosynthesis of $S$. polyrhiza, including both light-dependent reactions and the Calvin cycle, was enhanced by coculture with SP4.

Previous studies have revealed enhanced growth and yield of rice through the improvement in both $\mathrm{N}$ content and photosynthesis rate by inoculated rhizobia strains (Chi et al. 2005; Peng et al. 2002). To the best of our knowledge, the present study is the first to report enhanced growth of the duckweed $S$. polyrhiza by the PGPB Ensifer sp. SP4 through an increase in both N content and photosynthesis rate.

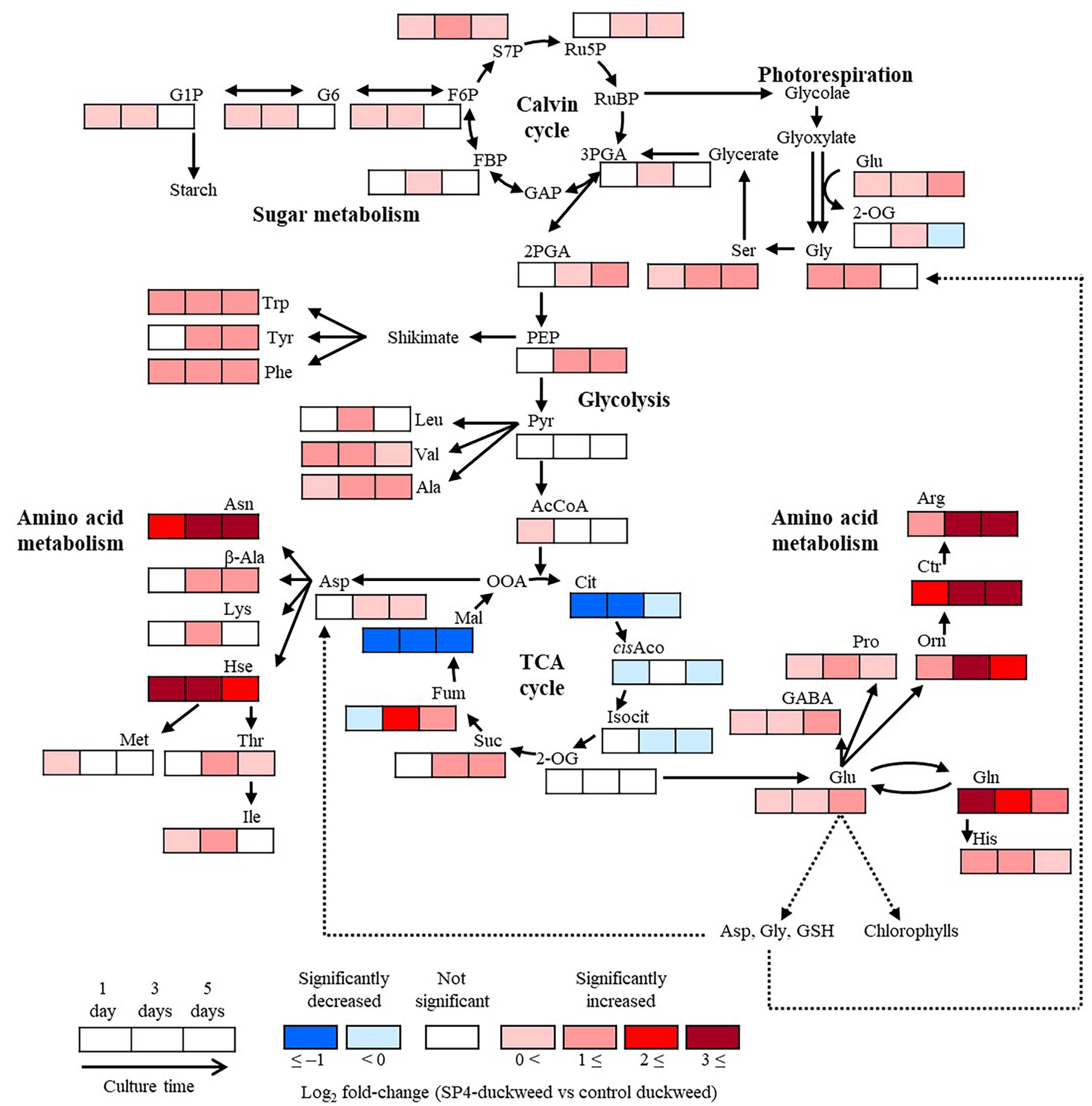

Fig. 4. Assignment of detected metabolites in Calvin cycle, photorespiration, sugar metabolism, glycolysis, tricarboxylic acid (TCA) cycle, and amino acid metabolism pathways. Triple boxes indicate the metabolites' $\log _{2}$ fold-change values (Spirodela polyrhiza in coculture with SP4 versus sterile control culture). Red indicates significant increase, blue indicates significant decrease, and white indicates no significant change. Abbreviations of metabolite names are defined in Supplementary Table S2. 
Conversely, the starch content of $S$. polyrhiza, recognized as $\mathrm{C}$ storage, did not increase after coculture with SP4. Moreover, the frond size and weight of $S$. polyrhiza plants became only slightly larger after coculture with SP4. Therefore, the C fixed by enhanced photosynthesis in S. polyrhiza after coculture with SP4 may predominantly be used for faster daughter frond biomass production (i.e., asexual reproduction) as opposed to increases in C storage and the size of the $S$. polyrhiza plant.

Plants can absorb and assimilate organic $\mathrm{N}$ compounds as well as inorganic $\mathrm{N}$ compounds (Näsholm et al. 2009). In the present study, the increased $\mathrm{N}$ content (from 2.5 to $6.3 \%$ ) and $\delta^{15} n$ values $(-0.83$ to $3.5 \%$ o $)$ in S. polyrhiza after coculture with SP4 (Fig. 2) indicate that $S$. polyrhiza absorbed N compounds released from SP4 $\left(\delta^{15} n=5.5 \%\right)$, not from the $\mathrm{N}$ source in Hoagland medium or from fixed atmospheric $\mathrm{N}$, because the $\delta^{15} n$ values of $\mathrm{KNO}_{3}$ in Hoagland medium and atmospheric $\mathrm{N}_{2}$ are -3.0 and $0 \%$, respectively. The metabolome analysis for SP4 cells indicated that SP4 produced various $\mathrm{N}$ compounds as diverse amino acids, nucleotides, GSH, and GSSG (Supplementary Table S2). These organic N compounds might then be absorbed and trigger the above increase in $\mathrm{N}$ content and enhanced photosynthesis of $S$. polyrhiza after coculture with SP4. Because the metabolome profiles of $S$. polyrhiza cocultured with SP4 differed substantially from those of SP4 (Supplementary Fig. S2), S. polyrhiza might take up the specific N compounds supplied by SP4 instead of all N compounds evenly.

Although the absorbed N compounds in S. polyrhiza were not identified or quantified in this study, Glu might be a key N compound for enhanced photosynthesis and growth in $S$. polyrhiza because Glu was detected at high levels in SP4 cell extraction (Supplementary Table S2). Furthermore, the concentrations of Glu and Gln, which can be synthesized via the Gln synthetase or Glu synthase cycle, were significantly higher in $S$. polyrhiza coculture with SP4 than in the control sterile S. polyrhiza (Figs. 3 and 4; Supplementary Fig. S2; Supplementary Table S2). Glu is a central molecule in amino acid metabolisms in higher plants (Forde and Lea 2007; Kissen et al. 2010) and an important precursor of protein amino acids, such as Gln, Pro, Arg, His, and Asn, as well as nonprotein amino acids (GABA) (Forde and Lea 2007; Kissen et al. 2010). Glu and various amino acids derived from Glu were significantly elevated in $S$. polyrhiza after coculture with SP4 (Figs. 3 and 4). These amino acids may become synthesized into proteins, after which a large amount of proteins may be used for $\mathrm{RuBisCO}$ synthesis, leading to enhanced photosynthesis. Glu is also a precursor of chlorophylls (Forde and Lea 2007; Reinbothe and Reinbothe 1996), which promotes photosynthesis. In addition, Glu plays important roles in plant growth, development, and response to environmental stresses (Qiu et al. 2020), including germination (Kong et al. 2015), root architecture (Forde et al. 2013), pathogen resistance (Jin et al. 2019), and response or adaptation to environmental stress (Kissen et al. 2010; Li et al. 2019). These findings support the notion that Glu might be a key molecular trigger for enhanced photosynthesis and growth of $S$. polyrhiza after coculture with SP4. On the other hand, Glu also inhibits the primary root growth of plants (Walch-Liu et al. 2006). Glu might also be involved in the phenomenon of shorter roots of S. polyrhiza after coculture with SP4 (Supplementary Fig. S1).

The metabolomic profile of $S$. polyrhiza was dramatically altered following coculture with SP4 and continued to change throughout the coculture (Figs. 3 and 4; Supplementary Fig. S2). The levels of amino acids in $S$. polyrhiza were particularly increased after coculture with SP4 compared with the levels of metabolites in the Calvin cycle, glycolysis, sugar metabolism, photorespiration, and TCA cycle (Figs. 3 and 4; Supplementary Fig. S2). These increased levels of amino acids might result from the N compounds supplied by SP4. Glu supplied by SP4 can be widely converted to various amino acids (Forde and Lea
2007; Kissen et al. 2010). In addition, the metabolites of the TCA cycle and Pyr might be converted to amino acids in $S$. polyrhiza after coculture with SP4 (Fig. 4). Several amino acids can act as signaling molecules (Häusler et al. 2014) and are precursors for the synthesis of secondary metabolites or phytohormones that exhibit multiple biological functions, health-promoting properties, immune enhancement, and reduction of abiotic stress (Batista-Silva et al. 2019). In particular, Pro and GABA, which are synthesized from Glu, exhibit many significant functions, including stress enhancement, reactive oxygen species scavenging, root elongation, growth promotion, seed germination, and enhanced photosynthesis (Kavi Kishor et al. 2015; Mattioli et al. 2009). Therefore, the enhanced amino acid metabolism in $S$. polyrhiza after coculture with SP4 might also lead to biomass promotion in multiple ways.

The present study demonstrated improved growth, $\mathrm{N}$ content, and photosynthesis rate of $S$. polyrhiza through its interactions with SP4, through analysis of the physiological (growth and photosynthesis), biochemical ( $\mathrm{C}, \mathrm{N}$, chlorophyll, and RuBisCO content; and $\mathrm{C}$ and $\mathrm{N}$ stable isotope ratios), and metabolomic responses of duckweed. Based on the results, we established a molecular mechanism model of the S. polyrhiza-SP4 interactions for S. polyrhiza growth promotion by SP4 (Fig. 5). The steps are as follows: (i) $S$. polyrhiza absorbs organic N compounds supplied by SP4, in which Glu might be a key molecule; (ii) high levels of $\mathrm{N}$ are allocated as amino acids, chlorophyll, and RuBisCO in S. polyrhiza; (iii) light-dependent reactions and the Calvin cycle are enhanced; (iv) therefore, biomass production and growth (asexual reproduction) of $S$. polyrhiza are promoted; and (v) enhanced amino acid metabolism contributes to the growth and health of $S$. polyrhiza. In this study, the metabolome of SP4 was extracted from its intracellular and not extracellular environment. To obtain a deeper understanding of $S$. polyrhiza-SP4 interactions, the extracellular metabolome of SP4 should be investigated. This study clearly showed the physicochemical, biochemical, and metabolomic characteristics of $S$. polyrhiza after 1 day of coculture with SP4. More rapid response of $S$. polyrhiza in coculture with SP4 within $24 \mathrm{~h}$ are also very interesting. In future studies, the rapid response of $S$. polyrhiza to SP4 will be necessary to a better understanding of S. polyrhiza-SP4 interactions.

In conclusion, Ensifer sp. SP4 isolated from S. polyrhiza significantly promoted the biomass production of $S$. polyrhiza through enhanced $\mathrm{N}$ compound metabolism and photosynthesis. The proposed $S$. polyrhiza-SP4 interaction mechanisms provide new insights into duckweed-PGPB interactions in aquatic ecosystems. These duckweed-associated bacteria interactions appear to increase duckweed productivity in natural aquatic ecosystems. Furthermore, this study highlights SP4 as a promising and useful PGPB for increasing the biomass yield, wastewater treatment performance, and $\mathrm{CO}_{2}$ fixation of $S$. polyrhiza.

\section{MATERIALS AND METHODS}

\section{Plant material and growth conditions.}

Duckweed (S. polyrhiza (L.) Schleid. strain UY0001), originally collected from a freshwater pond in Kofu, Yamanashi, Japan, was surface sterilized by washing in $0.5 \%$ sodium hypochlorite for 3 min, $70 \%$ ethanol for $1 \mathrm{~min}$, and sterilized water three times for 1 min. Bacteria-free $S$. polyrhiza was aseptically cultured in flasks containing sterile modified Hoagland solution $\left(\mathrm{KNO}_{3}\right.$ at $36.1 \mathrm{mg}$ liter ${ }^{-1}, \mathrm{~K}_{2} \mathrm{SO}_{4}$ at $293 \mathrm{mg}$ liter ${ }^{-1}, \mathrm{NaH}_{2} \mathrm{PO}_{4}$ at $3.87 \mathrm{mg} \mathrm{liter}^{-1}$, $\mathrm{MgSO}_{4} \cdot 7 \mathrm{H}_{2} \mathrm{O}$ at $103 \mathrm{mg} \mathrm{liter}{ }^{-1}, \mathrm{CaCl}_{2} \cdot \mathrm{H}_{2} \mathrm{O}$ at $147 \mathrm{mg} \mathrm{liter}^{-1}$ $\mathrm{FeSO}_{4} \cdot 7 \mathrm{H}_{2} \mathrm{O}$ at $3.33 \mathrm{mg} \mathrm{liter}^{-1}, \mathrm{H}_{3} \mathrm{BO}_{3}$ at $0.95 \mathrm{mg} \mathrm{liter}^{-1}$, $\mathrm{MnCl}_{2} \cdot 4 \mathrm{H}_{2} \mathrm{O}$ at $0.39 \mathrm{mg} \mathrm{liter}^{-1}, \mathrm{CuSO}_{4} \cdot 5 \mathrm{H}_{2} \mathrm{O}$ at $0.03 \mathrm{mg} \mathrm{liter}^{-1}$, $\mathrm{ZnSO}_{4} \cdot 7 \mathrm{H}_{2} \mathrm{O}$ at $0.08 \mathrm{mg} \operatorname{liter}^{-1}$, and $\mathrm{H}_{2} \mathrm{MoO}_{4} \cdot 4 \mathrm{H}_{2} \mathrm{O}$ at 
$0.254 \mathrm{mg} \mathrm{liter}^{-1} ; \mathrm{pH}$ 7.0) (Arnon and Hoagland 1940) in a plant growth room $\left(28 \pm 1{ }^{\circ} \mathrm{C}\right.$, fluorescent lamps at a photosynthetic photon flux density of $150 \mu \mathrm{mol} \mathrm{m} \mathrm{m}^{-2} \mathrm{~s}^{-1}$, photoperiod of $16 \mathrm{~h}$ of light and $8 \mathrm{~h}$ of darkness).

\section{Isolation of PGPB Ensifer sp. SP4 from S. polyrhiza.}

In this study, PGPB candidate bacterial strains were isolated from the surface of whole $S$. polyrhiza, which included the rhizosphere and phyllosphere, cultured in municipal wastewater effluent that was collected from the final settling tank in the municipal wastewater treatment plant of Kofu City, Yamanashi, Japan. The effluent sample was first passed through a glass microfiber filter (pore size $=1 \mu \mathrm{m}, \mathrm{GF} / \mathrm{B}$ grade; GE Healthcare UK Ltd., Buckinghamshire, England) to remove suspended solids and organisms larger than bacteria from the effluent sample. Thirty sterile $S$. polyrhiza plants were transferred to $200 \mathrm{ml}$ of effluent filtrate in a 500-ml glass flask and cultured in the plant growth room for 7 days. Next, 30 plants of $S$. polyrhiza were collected and transferred to $200 \mathrm{ml}$ of fresh effluent and cultured for 7 days. This 7-day batch culture growth was repeated once more. After the third batch culture, $10 \mathrm{~S}$. polyrhiza plants were collected from the flask, washed in $20 \mathrm{ml}$ of sterile Hoagland solution in a Petri dish, and transferred to a 50-ml tube containing $20 \mathrm{ml}$ of sterile Hoagland solution. The tube was vortexed at maximum speed for $3 \mathrm{~min}$, ultrasonicated $(40 \mathrm{kHz})$ for $1 \mathrm{~min}$, and vortexed again to disperse bacterial cells from the $S$. polyrhiza surface. The bacterial suspension was serially diluted and spread on 1:10 diluted tryptic soy (original content: digest of casein at $17 \mathrm{~g} \mathrm{liter}^{-1}$, digest soybean at $3 \mathrm{~g} \mathrm{liter}^{-1}$, dextrose at $2.5 \mathrm{~g} \mathrm{liter}^{-1}, \mathrm{NaCl}$ at $5 \mathrm{~g} \mathrm{liter}^{-1}$, and $\mathrm{K}_{2} \mathrm{HPO}_{4}$ at $2.5 \mathrm{~g}$ $\operatorname{liter}^{-1}$; pH 7.3) agar (1.5\% [wt/vol]) plates. The plates were then incubated at $28^{\circ} \mathrm{C}$ for 14 days. In total, 11 different bacterial strains were obtained, and each pure culture of each strain was maintained on a 1:10 diluted tryptic soy agar plate. Among the isolated bacterial strains, SP4 showed the highest duckweed growth-promoting ability and, thus, was selected for use in subsequent experiments.

\section{Identification and characterization}

of the plant-growth-promoting traits of SP4.

Physiological characterization was performed using an API 20NE kit according to the manufacturer's instructions (BioMérieux Japan, Tokyo, Japan). Sequencing and phylogenetic analysis of the 16S rRNA gene of SP4 were performed as follows: nearly complete $16 \mathrm{~S}$ rRNA genes were amplified by PCR using primers $8 \mathrm{~F}$ (5'-AGAGTTTGATCCTGGCTCAG- $\left.3^{\prime}\right)$ (Edwards et al. 1989) and 1510R (5'-GGTTACCTTGTTACGACTT-3') (Reysenbach et al. 1994). Genus-level identification was performed based on $16 \mathrm{~S}$ rRNA gene sequence similarity with that of a type strain sequence in NCBI GenBank using BLAST. The $16 \mathrm{~S}$ rRNA sequence data $(1,405 \mathrm{bp})$ of SP4 was submitted to the DNA Data Bank of Japan/European Nucleotide Archive/GenBank databases under accession number LC543984.

IAA production in the presence of L-tryptophan was tested according to a previously reported method (Rahman et al. 2010), with some modifications. The bacterial colony was inoculated and incubated in $10 \mathrm{ml}$ of 1:5 diluted tryptic soy medium with $0.05 \%$ (wt/vol) L-tryptophan at $28^{\circ} \mathrm{C}$ and $150 \mathrm{rpm}$ for 2 days. The culture was collected and centrifuged $\left(5,000 \times \mathrm{g}, 10 \mathrm{~min}, 24^{\circ} \mathrm{C}\right)$, and $500 \mu \mathrm{l}$ of supernatant was mixed with $750 \mu \mathrm{l}$ of Salkowski reagent ( $98 \mathrm{ml}$ of $35 \% \mathrm{HClO}_{4}$ and $2 \mathrm{ml}$ of $0.5 \mathrm{M} \mathrm{FeCl}_{3}$ ) in a tube. The mixture was placed at $24^{\circ} \mathrm{C}$ for $30 \mathrm{~min}$. A pink color indicated the production of IAA. Bacterial siderophore production was tested using the chrome azurol S (CAS) assay (Schwyn and Neilands 1987). The bacterial colony was streaked on CAS agar plates containing blue dye, which were incubated at $28^{\circ} \mathrm{C}$ for 7 days. A yellow or orange color around the colonies indicated the production of siderophore. P-solubilizing ability was assessed using Pikovskaya's agar containing $\mathrm{Ca}\left(\mathrm{PO}_{4}\right)_{2}$ as an insoluble phosphate (Nautiyal 1999). The bacterial colony was then streaked on Pikovskaya's agar and incubated at $28^{\circ} \mathrm{C}$ for 7 days. Clear zones around colonies indicated positive $\mathrm{P}$-solubilizing ability. $\mathrm{N}$-fixation ability was tested using a bacterial culture on a Jensen's N-free agar plate (sucrose at $20 \mathrm{~g} \mathrm{liter}^{-1}, \mathrm{~K}_{2} \mathrm{HPO}_{4}$ at $1 \mathrm{~g} \mathrm{liter}^{-1}, \mathrm{MgSO}_{4}$ at $0.5 \mathrm{~g}$ liter $^{-1}, \mathrm{NaCl}$ at $0.5 \mathrm{~g} \mathrm{liter}^{-1}, \mathrm{FeSO}_{4} \cdot 7 \mathrm{H}_{2} \mathrm{O}$ at $0.1 \mathrm{~g} \mathrm{liter}^{-1}, \mathrm{Na}_{2} \mathrm{MoO}_{4}$ at $0.005 \mathrm{~g} \mathrm{liter}^{-1}, \mathrm{CaCO}_{3}$ at $2 \mathrm{~g} \mathrm{liter}^{-1}$, and $1.5 \%$ [wt/vol] agar; $\mathrm{pH}$ 7.2) (Das and De 2018) for 7 days. Bacterial growth indicated positive N-fixation ability. Additionally, the presence of the nifH (encoding the nitrogenase reductase subunit) gene was also determined by PCR using the nifH1 ( $5^{\prime}$-ADNGCCATCATYTCNCC-3')/ nifH2 (5'-TGYGAYCCNAARGCNGA-3') primer set to support the findings of the N-fixation assay (Gaby and Buckley 2012).

\section{S. polyrhiza coculture with SP4 in Hoagland solution.}

A loop of the SP4 colony was inoculated and incubated in 200 $\mathrm{ml}$ of 1:5 diluted tryptic soy medium in 500-ml flasks for the late logarithmic growth phase at $28^{\circ} \mathrm{C}$ with shaking at $150 \mathrm{rpm}$. Cells were harvested by two cycles of centrifugation $(10,000 \times g$, room

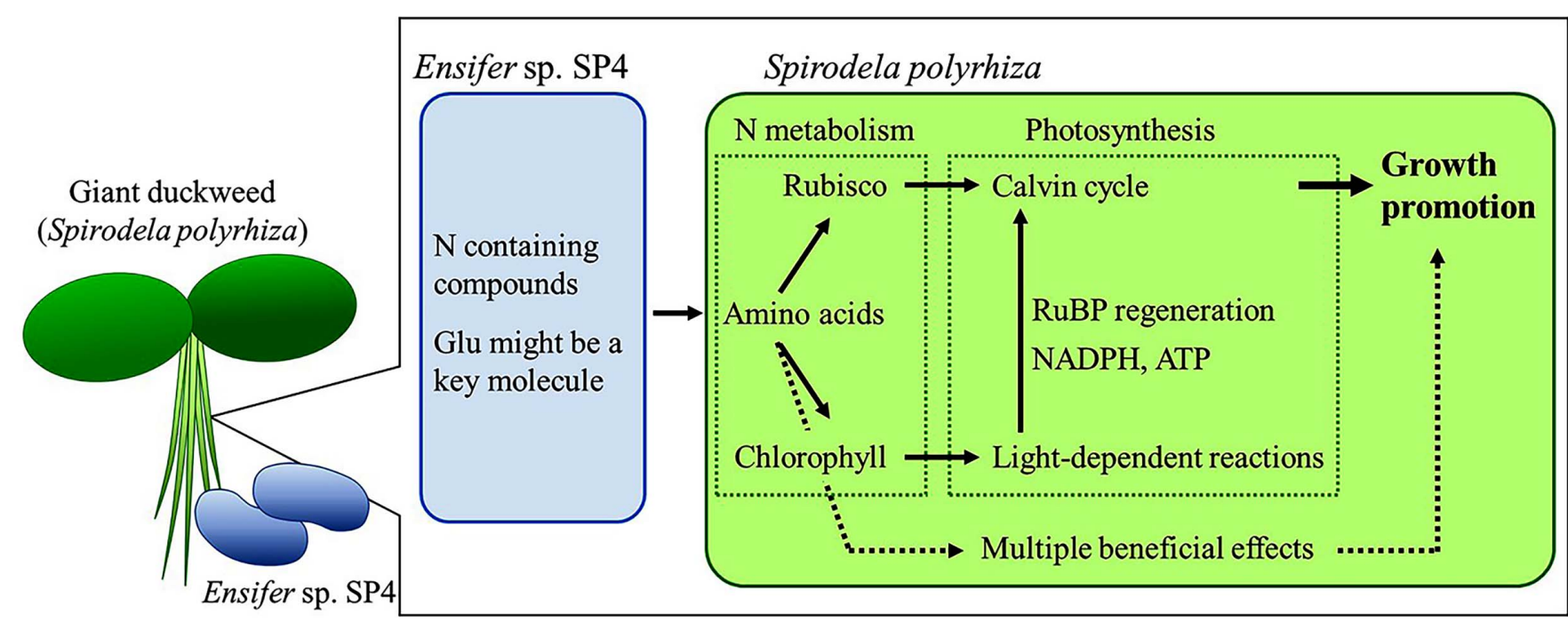

Fig. 5. Simple model of Spirodela polyrhiza-SP4 interaction mechanisms for S. polyrhiza growth promotion by SP4 through nitrogen (N) compound secretion based on physiological, biochemical, $\mathrm{N}$ stable isotope, and metabolomic analyses. 
temperature $\left[24^{\circ} \mathrm{C}\right], 5 \mathrm{~min}$ ) and washing for $30 \mathrm{~s}$ in sterilized Hoagland solution. The SP4 cells were suspended in $200 \mathrm{ml}$ of Hoagland solution at an optical density at $600 \mathrm{~nm}$ of 0.1 , which was approximately equal to $0.046 \mathrm{mg}$ dry cells $\mathrm{ml}^{-1}$ and approximately $1 \times 10^{7} \mathrm{CFU} \mathrm{ml}^{-1}$, in a 500-ml flask (diameter, $110 \mathrm{~mm}$ ). For coculture with SP4, 20 fronds of $S$. polyrhiza were transferred to SP4 suspended Hoagland solution $(200 \mathrm{ml})$ and cultured in the plant growth room (photoperiod of $16 \mathrm{~h}$ of light and $8 \mathrm{~h}$ of darkness) for 5 days. Sterile $S$. polyrhiza was also cultured in $200 \mathrm{ml}$ of sterilized Hoagland solution without SP4 cells under the same conditions as the sterile control. Eighteen replicate flasks were prepared for both the $S$. polyrhiza coculture with SP4 and the sterile control. During the experiments, the number of fronds, dry weight of $S$. polyrhiza, chlorophyll $a+b$ content, photosynthesis rate, biochemical properties, and metabolome of $S$. polyrhiza were determined. The sampling was conducted at the same clock time ( $5 \mathrm{~h}$ passed from lighting each day) to remove light condition effects on S. polyrhiza. Each parameter was analyzed in triplicate.

\section{Analytical procedure.}

All $S$. polyrhiza samples were collected from three flasks and dried at $70^{\circ} \mathrm{C}$ for $24 \mathrm{~h}$, after which the dry weight was determined. The relative growth rate (per day) was calculated using the increase in dry weight biomass and as previously described (Ziegler et al. 2015). The biomass production rate (milligrams of dry weight per day) was calculated using the increase in dry weight biomass during the 5-day cultivation. Chlorophyll content was determined by spectrophotometric analysis after extraction in $100 \%$ methanol. Six mature fronds of $S$. polyrhiza were transferred to a test tube, and chlorophyll was extracted using $5 \mathrm{ml}$ of methanol at room temperature $\left(24^{\circ} \mathrm{C}\right)$ in the dark for $1 \mathrm{~h}$. Absorbance (Abs) of the extract was measured at $665 \mathrm{~nm}\left(\mathrm{Abs}_{665}\right)$ and $650 \mathrm{~nm}\left(\mathrm{Abs}_{650}\right)$ using a spectrophotometer (UVmini-1240; Shimadzu Co. Ltd., Kyoto, Japan). Chlorophyll $a+b$ content (micrograms per milliliter) in the extract was calculated using the formula $4 \times \mathrm{Abs}_{665}+25.5 \times \mathrm{Abs}_{650}$ (Hipkins and Baker 1985). Subsequently, the chlorophyll $a+b$ content (micrograms per micrograms dry weight) in $S$. polyrhiza biomass was calculated. The RuBisCO content was determined using $500 \mathrm{mg}$ (wet weight) of $S$. polyrhiza sample and a RuBisCO ELISA quantitation kit (Agrisera, Vännäs, Sweden), according to the manufacturer's protocol.

The photosynthetic rate $\left(\mathrm{CO}_{2}\right.$ gas absorption rate) was measured using a portable photosynthesis system (LI-6400XTP; LI-COR Inc., Lincoln, NE, U.S.A.) equipped with a custom duckweed chamber (120 $\mathrm{mm}$ in diameter by $60 \mathrm{~mm}$ in height; LI-COR Inc.). Approximately $60 \mathrm{~S}$. polyrhiza fronds were collected from the flask and transferred to a Petri dish containing $20 \mathrm{ml}$ of Hoagland solution. The Petri dish was placed in the duckweed chamber. The photosynthesis system and chamber were set in the plant growth room. The $\mathrm{CO}_{2}$ concentration and photon irradiance in the chamber were set to $400 \mu \mathrm{mol} \mathrm{mol}{ }^{-1}$ and $150 \mu \mathrm{mol} \mathrm{m}{ }^{-2} \mathrm{~s}^{-1}$, respectively. After measurement, $S$. polyrhiza was collected and dried (at $70^{\circ} \mathrm{C}$ for $24 \mathrm{~h}$ ), and the dry weight was determined. The photosynthesis rate (i.e., the $\mathrm{CO}_{2}$ absorption rate in nanomoles of $\mathrm{CO}_{2}$ per milligram dry weight per second) was then calculated.

Dried S. polyrhiza biomass was powdered and used for biochemical analyses. The total $\mathrm{C}$ and $\mathrm{N}$ content (percent) as well as the isotope ratios of $\mathrm{C}\left({ }^{13} \mathrm{C} /{ }^{12} \mathrm{C}\right)$ and $\mathrm{N}\left({ }^{15} \mathrm{~N} /{ }^{14} \mathrm{~N}\right)$ in plant biomass samples were measured using a stable isotope analysis system (ANCA-GSL, Hydra 20-20; Sercon Ltd., Crewe, U.K.). C and $\mathrm{N}$ isotope compositions were calculated as $\delta^{13} \mathrm{C}$ or $\delta^{15} \mathrm{~N}$ $(\%)=[(\mathrm{R}$ sample/R standard $)-1] \times 1,000$, where $\mathrm{R}$ is the ratio of ${ }^{13} \mathrm{C} /{ }^{12} \mathrm{C}$ or ${ }^{15} \mathrm{~N} /{ }^{14} \mathrm{~N}$. Stable isotope ratios were determined using an internationally recognized standard and relative to a laboratory standard. In addition to $S$. polyrhiza biomass, C and $\mathrm{N}$ content and $\delta^{13} \mathrm{C}$ and $\delta^{15} n$ values of SP4 cells were determined. SP4 cells were cultured in 1:5 diluted tryptic soy medium until the late logarithmic growth phase at $28^{\circ} \mathrm{C}$ with shaking at $150 \mathrm{rpm}$ under the same conditions as the coculture experiment. SP4 cells were harvested by two cycles of centrifugation $\left(10,000 \times g\right.$, room temperature $\left.\left[24^{\circ} \mathrm{C}\right], 5 \mathrm{~min}\right)$ and washing for $30 \mathrm{~s}$ in sterilized Hoagland solution. The SP4 cells were dried at $70^{\circ} \mathrm{C}$ for $24 \mathrm{~h}$, then subjected to the $\mathrm{C}$ and $\mathrm{N}$ content and $\delta^{13} \mathrm{C}$ and $\delta^{15} n$ value analyses. Also, $\mathrm{KNO}_{3}$, which was used in the $S$. polyrhiza culture Hoagland solution as the $\mathrm{N}$ source, was subjected to the $\mathrm{N}$ content and $\delta^{15} n$ value analyses. The starch content was measured using a total starch assay kit (Megazyme International, Wicklow, Ireland). The protein content was measured using the total-N determination method (crude protein $=6.25 \times$ total $-\mathrm{N})($ Casal et al. 2000$)$.

\section{Metabolite extraction for $S$. polyrhiza biomass and strain SP4 cells.}

S. polyrhiza plants (200 mg wet weight) were collected from three flasks and immediately washed five times using a $25-\mathrm{ml}$ sterilized Hoagland solution in a 50-ml tube, followed by freezing in liquid $\mathrm{N}$ and storage at $-80^{\circ} \mathrm{C}$. For extraction of metabolites, the sample was transferred to a 4-ml cryotube containing Zirconia beads, with $1 \mathrm{ml}$ of methanol. The cryotube was shaken twice by a beads-shocker at $1,500 \mathrm{rpm}$ and $4^{\circ} \mathrm{C}$ for $120 \mathrm{~s}$. Then, $1 \mathrm{ml}$ of chloroform and $0.4 \mathrm{ml}$ of Milli-Q water were added to the tube, vortexed for $30 \mathrm{~s}$, then centrifuged $\left(2,300 \times g, 4^{\circ} \mathrm{C}, 5 \mathrm{~min}\right)$. The water phase $(0.4 \mathrm{ml})$ was carefully collected and transferred to a prewashed microcentrifuge filter tube (Millipore Ultrafree-MC PLHCC HMT; Millipore) and centrifuged $\left(9,100 \times g, 4^{\circ} \mathrm{C}, 120\right.$ $\min )$. The filtrates containing the metabolites were dried under a vacuum. The dried sample was resolved in $50 \mu \mathrm{l}$ of Milli-Q water and subjected to metabolome analysis.

In addition to $S$. polyrhiza, SP4 cells were subjected to metabolome analysis. SP4 cells were cultured in 1:5 diluted tryptic soy medium until the late logarithmic growth phase at $28^{\circ} \mathrm{C}$ with shaking at $150 \mathrm{rpm}$ under the same conditions as the coculture experiment. SP4 cells were harvested by two cycles of centrifugation $\left(10,000 \times \mathrm{g}\right.$, room temperature $\left.\left[24^{\circ} \mathrm{C}\right], 5 \mathrm{~min}\right)$ and washing for $30 \mathrm{~s}$ in sterilized Hoagland solution. The SP4 cells (approximately $10^{9}$ cells = approximately $0.05 \mathrm{mg}$ ) were then collected and filtered using a membrane filter (pore size $=0.2$ $\mu \mathrm{m}$; Merck Millipore Ltd., Cork, Ireland). The cells collected on the filter were washed twice with Hoagland solution, immersed in $2 \mathrm{ml}$ of methanol containing $5 \mu \mathrm{M}$ each internal standards methionine sulfone and D-camphor-10-sulfonic acid, and sonicated for $30 \mathrm{~s}$ to fully suspend the cells. A 1.6-ml portion of the methanol cell suspension was transferred to a $15-\mathrm{ml}$ Falcon Blue centrifugal tube (Becton Dickinson \& Co.), mixed with $1.6 \mathrm{ml}$ of chloroform and $0.64 \mathrm{ml}$ of Milli-Q water, and subsequently vortexed for $30 \mathrm{~s}$. The mixture was then centrifuged $\left(4,600 \times g, 4^{\circ} \mathrm{C}, 5\right.$ $\min )$. The aqueous phase $(0.75 \mathrm{ml})$ was distributed to three Amicon Ultrafree-MC ultrafilter tips (Merck Millipore Ltd.) and centrifuged $\left(9,100 \times g, 4^{\circ} \mathrm{C}, 120 \mathrm{~min}\right)$. The filtrates containing the metabolites were dried under a vacuum and resolved in $50 \mu \mathrm{l}$ of Milli-Q water before metabolome analysis.

\section{Metabolome analysis.}

Metabolome analysis was conducted at Human Metabolome Technologies (HMT), Japan, using a CE-TOFMS system (Agilent Technologies Inc., Santa Clara, CA, U.S.A.) in anion and cation modes. A fused silica capillary (internal diameter $50 \mu \mathrm{m}, 80 \mathrm{~cm}$ long) was used. The run and rinse buffers were cation buffer solution (p/n: H3301-1001) for cation mode and anion buffer solution (p/n: I3302-1023) for anion mode. Electrospray ionization (ESI)MS was conducted for both modes. The sample injection pressure was 50 mbar for $10 \mathrm{~s}$ (cation mode) or 50 mbar for $25 \mathrm{~s}$ (anion mode). The $\mathrm{CE}$ voltage parameters were either positive $27 \mathrm{kV}$ 
(cation mode) or positive $30 \mathrm{kV}$ (anion mode). MS ionization was either ESI positive (cation) or ESI negative (anion). The MS capillary voltage was either $4,000 \mathrm{~V}$ for cation mode or $3,500 \mathrm{~V}$ for anion mode, and the MS scan range was $\mathrm{m} / \mathrm{z} 50$ to 1,000 (both modes). The sheath liquid was either HMT Sheath Liquid (p/n: I3301-1020) (cation) or HMT Sheath Liquid (p/n: H3301-1020). The samples were diluted twofold for measurement in both modes to improve the analysis quantity during CE-MS analysis.

The peaks detected during CE-TOFMS analysis were extracted using automatic integration software (MasterHands ver. 2.13.0.8h; developed at Keio University) to obtain peak information, including $\mathrm{m} / \mathrm{z}$, migration time, and peak area. The peak area was then converted to the relative peak area (i.e., standardized data). The peak detection limit was determined based on a signal-to-noise ratio of 3 .

Absolute quantification was performed for 108 metabolites, including amino acids, organic acids, sugar phosphates, and nucleic acids. Metabolite concentrations were calculated by normalizing the peak area of each metabolite with respect to the area of the internal standard using standard curves, which were obtained by single-point $(100 \mu \mathrm{M})$ calibrations.

\section{Statistical and data analyses.}

Each value used in the statistical analysis represents the results from three samples $(n=3)$. Data are expressed as means \pm standard deviation. The significance $(P<0.05)$ was analyzed by the pairwise $t$ test using XLSTAT (version 2019; Addinsoft, Paris, France). For the metabolome analysis, the 58 quantified metabolites were normalized using the z-score and hierarchical cluster analysis based on Euclidian distances using XLSTAT.

\section{Data availability.}

For $S$. polyrhiza (L.) Schleid. strain UY0001, the DNA sequencing data of the atpF-atpH intergenic spacer was submitted to the GenBank databases under accession number LC549213.

\section{ACKNOWLEDGMENTS}

We thank T. Nakayama and A. Ichinose, who provided experimental support to the corresponding author's students.

\section{LITERATURE CITED}

Acosta, K., Xu, J., Gilbert, S., Denison, E., Brinkman, T., Lebeis, S., and Lam, E. 2020. Duckweed hosts a taxonomically similar bacterial assemblage as the terrestrial leaf microbiome. PLoS One 15:e0228560.

Appenroth, K. J., Borisjuk, N., and Lam, E. 2013. Telling duckweed apart: Genotyping technologies for the Lemnaceae. Yingyong $\mathrm{Yu}$ Huanjing Shengwu Xuebao 19:1-10.

Appenroth, K. J., Sree, K. S., Böhm, V., Hammann, S., Vetter, W., Leiterer, M., and Jahreis, G. 2017. Nutritional value of duckweeds (Lemnaceae) as human food. Food Chem. 217:266-273.

Arnon, D., and Hoagland, D. R. 1940. Crop production in artificial culture solutions and in soils with special reference to factors influencing yields and absorption of inorganic nutrients. Soil Sci. 50:463-485.

Bashan, Y., and Holguin, G. 1998. Proposal for the division of plant growth-promoting rhizobacteria into two classifications: BiocontrolPGPB (plant growth-promoting bacteria) and PGPB. Soil Biol. Biochem. 30:1225-1228.

Batista-Silva, W., Heinemann, B., Rugen, N., Nunes-Nesi, A., Araújo, W. L., Braun, H.-P., and Hildebrandt, T. M. 2019. The role of amino acid metabolism during abiotic stress release. Plant Cell Environ. 42: 1630-1644.

Bevins, M. A., Madhavan, S., and Markwell, J. 1993. Two sweetclover (Melilotus alba Desr.) mutants temperature sensitive for chlorophyll expression. Plant Physiol. 103:1123-1131.

Buchanan, B. B., Gruissem, W., and Jones, R. L. 2015. Biochemistry and Molecular Biology of Plants, 2nd Ed. John Wiley \& Sons, Ltd., Chichester, U.K.
Bulgarelli, D., Schlaeppi, K., Spaepen, S., Ver Loren van Themaat, E. and Schulze-Lefert, P. 2013. Structure and functions of the bacterial microbiota of plants. Annu. Rev. Plant Biol. 64:807-838.

Casal, J. A., Vermaat, J. E., and Wiegman, F. 2000. A test of two methods for plant protein determination using duckweed. Aquat. Bot. 67:61-67.

Cheng, J. J., and Stomp, A.-M. 2009. Growing duckweed to recover nutrients from wastewaters and for production of fuel ethanol and animal feed. Clean: Soil, Air, Water 37:17-26.

Chi, F., Shen, S.-H., Cheng, H.-P., Jing, Y.-X., Yanni, Y. G., and Dazzo, F. B. 2005. Ascending migration of endophytic rhizobia, from roots to leaves, inside rice plants and assessment of benefits to rice growth physiology. Appl. Environ. Microbiol. 71:7271-7278.

Cui, W., and Cheng, J. J. 2015. Growing duckweed for biofuel production: A review. Plant Biol. (Berlin, Ger.) 17:16-23.

Das, S., and De, T. K. 2018. Microbial assay of $\mathrm{N}_{2}$ fixation rate, a simple alternate for acetylene reduction assay. MethodsX 5:909-914.

Edwards, U., Rogall, T., Blöcker, H., Emde, M., and Böttger, E. C. 1989. Isolation and direct complete nucleotide determination of entire genes. Characterization of a gene coding for $16 \mathrm{~S}$ ribosomal RNA. Nucleic Acids Res. 17:7843-7853.

Evans, J. R. 1989. Photosynthesis and nitrogen relationships in leaves of $\mathrm{C}_{3}$ plants. Oecologia 78:9-19.

Forde, B. G., Cutler, S. R., Zaman, N., and Krysan, P. J. 2013. Glutamate signalling via a MEKK1 kinase-dependent pathway induces changes in Arabidopsis root architecture. Plant J. 75:1-10.

Forde, B. G., and Lea, P. J. 2007. Glutamate in plants: Metabolism, regulation, and signalling. J. Exp. Bot. 58:2339-2358.

Gaby, J. C., and Buckley, D. H. 2012. A comprehensive evaluation of PCR primers to amplify the nifH gene of nitrogenase. PLoS One 7:e42149.

Giehl, R. F. H., and von Wirén, N. 2014. Root nutrient foraging. Plant Physiol. 166:509-517.

Gilbert, S., Xu, J., Acosta, K., Poulev, A., Lebeis, S., and Lam, E. 2018. Bacterial production of indole related compounds reveals their role in association between duckweeds and endophytes. Front. Chem. 6:265.

Gopalakrishnan, S., Sathya, A., Vijayabharathi, R., Varshney, R. K., Gowda, C. L. L., and Krishnamurthy, L. 2015. Plant growth promoting rhizobia: Challenges and opportunities. 3 Biotech 5:355-377.

Häusler, R. E., Ludewig, F., and Krueger, S. 2014. Amino acids-A life between metabolism and signaling. Plant Sci. 229:225-237.

Hill, P. W., Handley, L. L., and Raven, J. A. 1996. Juniperus communis L. ssp. communis at Balnaguard, Scotland: Foliar carbon discrimination $\left(\delta^{13} \mathrm{C}\right)$ and $15-\mathrm{N}$ natural abundance $\left(\delta^{15} \mathrm{~N}\right)$ suggest gender-linked differences in water and N use. Bot. J. Scotl. 48:209-224.

Hipkins, M., and Baker, N. R. 1985. Photosynthetic Energy Transduction: A Practical Approach. IRL Press, Oxford, U.K.

Hodge, A. 2004. The plastic plant: Root responses to heterogeneous supplies of nutrients. New Phytol. 162:9-24.

Ishizawa, H., Kuroda, M., Morikawa, M., and Ike, M. 2017a. Evaluation of environmental bacterial communities as a factor affecting the growth of duckweed Lemna minor. Biotechnol. Biofuels 10:62.

Ishizawa, H., Kuroda, M., Morikawa, M., and Ike, M. 2017b. Differential oxidative and antioxidative response of duckweed Lemna minor toward plant growth promoting/inhibiting bacteria. Plant Physiol. Biochem. 118:667-673.

Ishizawa, H., Ogata, Y., Hachiya, Y., Tokura, K. I., Kuroda, M., Inoue, D., Toyama, T., Tanaka, Y., Mori, K., Morikawa, M., and Ike, M. 2020. Enhanced biomass production and nutrient removal capacity of duckweed via two-step cultivation process with a plant growth-promoting bacterium, Acinetobacter calcoaceticus $\mathrm{P} 23$. Chemosphere 238:124682.

Iwashita, T., Tanaka, Y., Tamaki, H., Yoneda, Y., Makino, A., Tateno, Y., Li, Y., Toyama, T., Kamagata, Y., and Mori, K. 2020. Comparative analysis of microbial communities in fronds and roots of three duckweed species: Spirodela polyrhiza, Lemna minor, and Lemna aequinoctialis. Microbes Environ. 35:ME20081.

Jin, L., Cai, Y., Sun, C., Huang, Y., and Yu, T. 2019. Exogenous L-glutamate treatment could induce resistance against Penicillium expansum in pear fruit by activating defense-related proteins and amino acids metabolism. Postharvest Biol. Technol. 150:148-157.

Kavi Kishor, P. B., Hima Kumari, P., Sunita, M. S. L., and Sreenivasulu, N. 2015. Role of proline in cell wall synthesis and plant development and its implications in plant ontogeny. Front. Plant Sci. 6:544.

Khairina, Y., Jog, R., Boonmak, C., Toyama, T., Oyama, T., and Morikawa, M. 2021. Indigenous bacteria, an excellent reservoir of functional plant growth promoters for enhancing duckweed biomass yield on site. Chemosphere 268:129247.

Kissen, R., Winge, P., Tran, D. H. T., Jørstad, T. S., Størseth, T. R., Christensen, T., and Bones, A. M. 2010. Transcriptional profiling of 
an Fd-GOGAT1/GLU1 mutant in Arabidopsis thaliana reveals a multiple stress response and extensive reprogramming of the transcriptome. BMC Genomics 11:190.

Kong, D., Ju, C., Parihar, A., Kim, S., Cho, D., and Kwak, J. M. 2015. Arabidopsis glutamate receptor homolog 3.5 modulates cytosolic $\mathrm{Ca}_{2}{ }^{+}$ level to counteract effect of abscisic acid in seed germination. Plant Physiol. 167:1630-1642.

Landolt, E., and Kandeler, R. 1987. The Family of Lemnaceae-A Monographic Study. Biosystematic Investigations in the Family of Duckweeds (Lemnaceae), vol. 2. Geobotanischen Institut ETH, Zürich, Switzerland.

Laranjo, M., Alexandre, A., and Oliveira, S. 2014. Legume growthpromoting rhizobia: An overview on the Mesorhizobium genus. Microbiol. Res. 169:2-17.

Li, Z. G., Ye, X. Y., and Qiu, X. M. 2019. Glutamate signaling enhances the heat tolerance of maize seedlings by plant glutamate receptor-like channels-mediated calcium signaling. Protoplasma 256:1165-1169.

Makino, A. 2003. Rubisco and nitrogen relationships in rice: Leaf photosynthesis and plant growth. Soil Sci. Plant Nutr. 49:319-327.

Mattioli, R., Costantino, P., and Trovato, M. 2009. Proline accumulation in plants. Plant Signal. Behav. 4:1016-1018.

Mohedano, R. A., Costa, R. H. R., Tavares, F. A., and Belli Filho, P. 2012. High nutrient removal rate from swine wastes and protein biomass production by full-scale duckweed ponds. Bioresour. Technol. 112:98-104.

Näsholm, T., Kielland, K., and Ganeteg, U. 2009. Uptake of organic nitrogen by plants. New Phytol. 182:31-48.

Nautiyal, C. S. 1999. An efficient microbiological growth medium for screening phosphate solubilizing microorganisms. FEMS Microbiol. Lett. 170:265-270.

Peng, S., Biswas, J. C., Ladha, J. K., Gyaneshwar, P., and Chen, Y. 2002. Influence of rhizobial inoculation on photosynthesis and grain yield of rice. Agron. J. 94:925-929.

Perchlik, M., and Tegeder, M. 2018. Leaf amino acid supply affects photosynthetic and plant nitrogen use efficiency under nitrogen stress. Plant Physiol. 178:174-188.

Qiu, X.-M., Sun, Y.-Y., Ye, X.-Y., and Li, Z.-G. 2020. Signaling role of glutamate in plants. Front. Plant Sci. 10:1743.

Rahman, A., Sitepu, I. R., Tang, S. Y., and Hashidoko, Y. 2010. Salkowski's reagent test as a primary screening index for functionalities of rhizobacteria isolated from wild dipterocarp saplings growing naturally on medium-strongly acidic tropical peat soil. Biosci. Biotechnol. Biochem. 74:2202-2208.

Reinbothe, S., and Reinbothe, C. 1996. The regulation of enzymes involved in chlorophyll biosynthesis. Eur. J. Biochem. 237:323-343.
Reysenbach, A. L., Wickham, G. S., and Pace, N. R. 1994. Phylogenetic analysis of the hyperthermophilic pink filament community in Octopus Spring, Yellowstone National Park. Appl. Environ. Microbiol. 60:2113-2119.

Schwyn, B., and Neilands, J. B. 1987. Universal chemical assay for the detection and determination of siderophores. Anal. Biochem. 160:47-56.

Sudo, E., Suzuki, Y., and Makino, A. 2014. Whole-plant growth and N utilization in transgenic rice plants with increased or decreased Rubisco content under different $\mathrm{CO}_{2}$ partial pressures. Plant Cell Physiol. 55: 1905-1911.

Terry, N. 1980. Limiting factors in photosynthesis: I. Use of iron stress to control photochemical capacity in vivo. Plant Physiol. 65:114-120.

Toyama, T., Hanaoka, T., Tanaka, Y., Morikawa, M., and Mori, K. 2018 Comprehensive evaluation of nitrogen removal rate and biomass, ethanol, and methane production yields by combination of four major duckweeds and three types of wastewater effluent. Bioresour. Technol. 250: 464-473.

van der Spiegel, M., Noordam, M. Y., and van der Fels-Klerx, H. J. 2013. Safety of novel protein sources (insects, microalgae, seaweed, duckweed, and rapeseed) and legislative aspects for their application in food and feed production. Compr. Rev. Food Sci. Food Saf. 12:662-678.

Walch-Liu, P., Liu, L.-H., Remans, T., Tester, M., and Forde, B. G 2006. Evidence that L-glutamate can act as an exogenous signal to modulate root growth and branching in Arabidopsis thaliana. Plant Cell Physiol. 47:1045-1057.

Willems, A., Fernández-López, M., Muñoz-Adelantado, E., Goris, J., De Vos, P., Martínez-Romero, E., Toro, N., and Gillis, M. 2003. Description of new Ensifer strains from nodules and proposal to transfer Ensifer adhaerens Casida 1982 to Sinorhizobium as Sinorhizobium adhaerens comb. nov. Request for an opinion. Int. J. Syst. Evol. Microbiol. 53:1207-1217.

Xu, J., Dolan, M. C., Medrano, G., Cramer, C. L., and Weathers, P. J. 2012a. Green factory: Plants as bioproduction platforms for recombinant proteins. Biotechnol. Adv. 30:1171-1184.

Xu, J., Zhao, H., Stomp, A.-M., and Cheng, J. J. 2012b. The production of duckweed as a source of biofuels. Biofuels 3:589-601.

Yamaga, F., Washio, K., and Morikawa, M. 2010. Sustainable biodegradation of phenol by Acinetobacter calcoaceticus P23 isolated from the rhizosphere of duckweed Lemna aoukikusa. Environ. Sci. Technol. 44: 6470-6474

Ziegler, P., Adelmann, K., Zimmer, S., Schmidt, C., and Appenroth, K. J. 2015. Relative in vitro growth rates of duckweeds (Lemnaceae)_-The most rapidly growing higher plants. Plant Biol. (Berlin, Ger.) 17:33-41. 